\title{
Real-World Outcome of 173 Metastatic Non-Clear Cell Renal Cell Carcinoma (nccRCC) Cases: The Experience of the Center Group for Genitourinary Tumors
}

Almudena Martín ${ }^{\mathrm{a}, *}$, Javier Puente $^{\mathrm{b}}$, Alvaro Pinto $^{\mathrm{c}}$, Pablo Gajate $^{\mathrm{d}}$, Teresa Alonso Gordoa ${ }^{\mathrm{d}}$, Enrique Grande $^{\mathrm{e}}$, Ana Herrero ${ }^{\mathrm{f}}$, Constanza Maximiano ${ }^{\mathrm{g}}$, Martía Garrido ${ }^{\mathrm{h}}$, Isabel Gallegos ${ }^{\mathrm{i}}$, M $^{\mathrm{a}}$ Laura Villalobos $^{\mathrm{j}}$, Jesús García-Donas ${ }^{\mathrm{k}}$, Edinson Caviedes ${ }^{\mathrm{l}}$, Iciar García ${ }^{\mathrm{m}}$, Javier Espinosa ${ }^{\mathrm{n}}$, Carlos Aguado ${ }^{\mathrm{b}}$, José Angel Arranz ${ }^{\mathrm{o}}$, Lourdes García ${ }^{\mathrm{i}}$, Juan Francisco Rodriguez ${ }^{\mathrm{k}}$, Javier Casinello ${ }^{\mathrm{p}}$ and Laura Rodriguez $\mathrm{q}^{\mathrm{q}}$

${ }^{a}$ Department of Medical Oncology, Hospital Universitario Infanta Leonor, Madrid, Spain

${ }^{\mathrm{b}}$ Department of Medical Oncology, Hospital Clínico San Carlos, Instituto de Investigación Sanitaria del Hospital Clínico San Carlos (IdISSC), CIBERONC, Madrid, Spain

${ }^{\mathrm{c}}$ Department of Medical Oncology, Hospital Universitario La Paz, Madrid, Spain

${ }^{\mathrm{d}}$ Department of Medical Oncology, Hospital Universitario Ramón y Cajal, Madrid, Spain

e Department of Medical Oncology, MD Anderson Cancer Center Madrid, Madrid, Spain

${ }^{\mathrm{f}}$ Department of Medical Oncology, OncoHealth Institute, Hospital Universitario Fundación Jiménez Díaz, Madrid, Spain

${ }^{\mathrm{g}}$ Department of Medical Oncology, Hospital Universitario Puerta de Hierro-Majadahonda, Majadahonda, Madrid, Spain

${ }^{\mathrm{h}}$ Department of Medical Oncology, Hospital Universitario Severo Ochoa, Leganés, Madrid, Spain

${ }^{\mathrm{i}}$ Department of Medical Oncology, Hospital General de Segovia, Segovia, Spain

${ }^{\mathrm{j}}$ Department of Medical Oncology, Hospital Universitario Príncipe de Asturias, Alcalá de Henares, Madrid, Spain

${ }^{\mathrm{k}}$ Department of Medical Oncology, HM Hospitales - Centro Integral Oncológico HM Clara Campal, Madrid, Spain

${ }^{1}$ Department of Medical Oncology, GenesisCare Madrid, Hospital La Milagrosa, Madrid, Spain

${ }^{\mathrm{m}}$ Department of Medical Oncology, Hospital Virgen de la Salud, Toledo, Spain

${ }^{\mathrm{n}}$ Department of Medical Oncology, Hospital General Universitario de Ciudad Real, Ciudad Real, Spain

${ }^{\circ}$ Department of Medical Oncology, Hospital General Universitario Gregorio Marañón, Madrid, Spain

${ }^{\mathrm{p}}$ Department of Medical Oncology, Hospital Universitario de Guadalajara, Guadalajara, Spain

${ }^{\mathrm{q}}$ Department of Medical Oncology, Hospital Universitario de Fuenlabrada, Fuenlabrada, Madrid, Spain

\footnotetext{
*Correspondence to: Almudena Martín Marino, Hospital de Día de Oncología, Hospital Universitario Infanta Leonor, Calle Gran Vía del Este 80, Madrid 28031, Spain. Tel.: +34 647666 413; Fax: +34 9119190 86; E-mail: almummarino@yahoo.es.
} 


\begin{abstract}
Non-clear cell renal cell carcinoma (nccRCC) represents a group of multiple histologic subtypes, with different clinical outcomes and an uncertain optimal treatment. Data collected in clear cell tumors are routinely extrapolated to nccRCC, despite a different underlying biology. The Center Group for Genitourinary tumors is a network of medical oncologists from hospitals in Madrid and surrounding provinces that are focused on genitourinary tumors. A retrospective, multicenter study of the outcome of patients with nccRCC diagnosed and treated at the Center Group hospitals between 1995 and 2015 was performed. Baseline clinical features, histologic subtypes, therapeutic management and survival status were analyzed. Data was collected from 173 patients, with a median age at diagnosis of 65 years [24-90], 67.1\% were male. Histologic subtypes comprised $55.5 \%$ papillary carcinoma, $23.1 \%$ sarcomatoid, $13.9 \%$ chromophobe, $6.9 \%$ unclassified tumors and $0.6 \%$ oncocytoma. 159 patients received first line therapy including tyrosine kinase inhibitors (67.9\%) and mammalian target of rapamycin inhibitors (11.9\%). The response rates (RR) in evaluable patients (142) were: complete response 5.6\%, partial response $17.6 \%$, stable disease $40.8 \%$ and progression in $35.9 \%$ of cases. 90 patients (52.0\%) received second line treatment. At the time of the data cut-off point (April 1, 2016), 126 patients had died, with a median overall survival (OS) of 17.9 months [95\% CI 15.0-20.9]. The clinical outcome reported in this study has a similar OS to other published studies. Nevertheless, there are substantial differences among the distinct subtypes. Overall, prognosis in nccRCC remains poor. No significant differences were observed in the activity of systemic agents, used as either first or second line therapy.
\end{abstract}

Keywords: Renal cell carcinoma, papillary, chromophobe, non-clear cell, molecular targeted therapy, tyrosine kinase inhibitor, mTOR inhibitor, survival

\section{INTRODUCTION}

Kidney cancer accounts for $3-5 \%$ of all solid tumors in adults [1]. Clear cell renal cell carcinoma (ccRCC) represents $75-80 \%$ of renal epithelial malignancies. The remaining histological subtypes are referred to as non-clear cell renal cell carcinomas. Papillary carcinoma is the most common variant in this group (10-15\% of renal cell carcinoma [RCC]) followed by chromophobe (5\%) [2]. Other histological subtypes include collecting duct with its medullary carcinoma variant, translocation and unclassified tumors. There is debate as to whether sarcomatoid tumors should be considered as non-clear cell RCC or should be classified as mesenchymal. A sarcomatoid component mixed with a predominant other histological type is relatively frequent. Usually, if this component represents less than $20 \%$ of the total sample, tumors are treated as if no sarcomatoid features were present. Actually, those patients with sarcomatoid features have a worse prognosis and are more resistant to standard systemic therapy options. Traditionally, treatment of metastatic ccRCC has been based on targeted therapies against vascular endothelial growth factor (VEGF), VEGF receptors (VEGFR) and mammalian target of rapamycin (mTOR). nccRCC represents a heterogeneous group with different biochemical features, genetic profiles, clinical characteristics and prognosis. The management of patients with nccRCC is unclear due to the infrequency of these histological types. They are usu- ally excluded from clinical trials and treated the same as ccRCC.

The "Center Group for Genitourinary tumors" is a network of medical oncologists focused on genitourinary tumors from hospitals in Madrid and the surrounding provinces. This study aimed to assess the clinical behavior and characterize the activity in the real-world practice of nccRCC patients treated in our centers over the last two decades.

\section{MATERIAL AND METHODS}

A retrospective, multicenter study was performed of patients with metastatic nccRCC diagnosed between 1995 and 2015. Data were collected from medical records at 14 hospitals that belong to the Center Group for Genitourinary tumors network. Inclusion criteria included: histologically confirmed diagnosis of nccRCC including papillary, oncocytoma, chromophobe, medullary, translocation, unclassified or a mixture of these variants; and ccRCC with predominant non-clear cell features or sarcomatoid component above $10 \%$. Exclusion criteria included: no previous history of invasive malignancy; a predominant clear cell component within a mixed histology, except if sarcomatoid features represented more than $10 \%$; and the inability to follow-up the patient after the diagnosis of advanced disease. Baseline clinical and disease characteristics, histologic subtypes, Memorial Sloan Kettering 
Cancer Center (MSKCC) score, treatment information, evaluation of response and survival status were recorded. The primary objective was to define the demographic baseline characteristics of nccRCC patients in our environment and to assess the clinical outcome in terms of overall survival (OS), objective responses and progression free survival in patients treated with systemic therapies. The study protocol was approved by the local institutional review board or ethics committee at each participating center.

\section{Statistical Analysis}

Descriptive statistics were used to assess patient and tumor characteristics. Categorical data are presented as absolute frequencies and percentages. The response rate was measured using the Response Evaluation Criteria in Solid Tumors (RECIST) criteria. The data collection cut-off point was April 1st 2016. Progression free survival (PFS) was defined as the time from the beginning of treatment for metastatic disease until tumor progression or death, whichever occurred first. Overall survival was defined as the time from diagnosis of metastatic disease to death. PFS and OS were estimated using Kaplan-Meier survival curve analysis. Exploratory analyses were performed to evaluate OS according to histology and MSKCC risk group. Statistical data analysis was performed using SPSS version 20 (IBM Corp., Armonk, NY).

\section{RESULTS}

A total of 173 patients were included in the study. Table 1 summarizes the baseline demographic and clinical characteristics of the study population. The median age was 65 (24-90) years old. Most patients were male $(67.1 \%)$ and had undergone a cytoreductive nephrectomy (85.5\%). Papillary carcinoma $(55.5 \%)$ and mixed tumors with sarcomatoid features $(23.1 \%)$ were the predominant histological types. More than half of patients $(55.5 \%)$ had advanced disease. Most papillary and sarcomatoid tumors were diagnosed at an advanced disease stage, whereas chromophobe presented as locally advanced tumors. Assignment according to MSKCC risk groups were: favorable $(21.4 \%)$, intermediate $(53.8 \%)$, poor $(20.2 \%)$ and unknown (4.6\%). Most patients with papillary $(53.1 \%)$ and sarcomatoid $(62.5 \%)$ tumors were rated as intermediate risk, whereas $45.8 \%$ of chromophobe tumors were rated as a good prognosis. Approximately $40 \%$ of patients
Table 1

Baseline demographic and clinical characteristics of patients $(\mathrm{N}=173)$

\begin{tabular}{lc}
\hline Characteristics & $\begin{array}{c}\text { Number of } \\
\text { patients (\%) }\end{array}$ \\
\hline Median age first diagnosis (range), years & $65(24-90)$ \\
Sex & \\
Male & $116(67.1 \%)$ \\
Female & $57(32.9 \%)$ \\
Stage at first diagnosis & \\
T1-T2 N0 M0 & $32(18.5 \%)$ \\
T3-T4 and/or N+M0 & $45(26.0 \%)$ \\
M1 & $96(55.5 \%)$ \\
Previous nephrectomy & \\
Yes & $148(85.5 \%)$ \\
No & $25(14.5 \%)$ \\
Histology & \\
Papillary & $96(55.5 \%)$ \\
Sarcomatoid & $40(23.1 \%)$ \\
Chromophobe & $24(13.9 \%)$ \\
Unclassified & $12(6.9 \%)$ \\
Oncocytoma & $1(0.6 \%)$ \\
Medullary & $0(0 \%)$ \\
MSKCC Risk Group & \\
Favorable & $37(21.4 \%)$ \\
Intermediate & $93(53.8 \%)$ \\
Poor & $35(20.2 \%)$ \\
Unknown & $8(4.6 \%)$ \\
Number of metastatic sites & \\
1 & $69(39.9 \%)$ \\
2 & $52(30.0 \%)$ \\
$\geq 3$ & $52(30.1 \%)$ \\
\hline
\end{tabular}

had metastatic lesions at one site at diagnosis (mainly lung).

$8.1 \%$ patients received best supportive care as the only systemic approach. 159 patients received first line therapy; $108(67.9 \%)$ patients were treated with VEGFR tyrosine kinase inhibitors (TKI), 89 (82.4\%) of them with sunitinib. Among the patients treated with mTOR inhibitor as a first line therapy (11.9\%), temsirolimus was prescribed in the majority of cases (89.5\%).

31 patients were not included in the response analysis: 14 did not receive any treatment, 6 had an unknown response or were lost to follow up and 11 were not assessable. The response rate (RR) based on RECIST criteria in 142 evaluable patients were: complete response $(5.6 \%)$, partial response $(17.6 \%)$, stable disease $(40.8 \%)$ and disease progression $(35.9 \%)$ (Table 2). A complete response was achieved with local treatment in 5 cases, TKI in 2 and chemotherapy in 1 case. Best responses to different treatments are shown in Fig. 1. The main reasons for discontinuing treatment were progression in $59.5 \%$ of patients and toxicity in $13.3 \%$ of cases. $52.0 \%$ of patients received a second line of treatment; TKI in 
Table 2

Treatment of metastatic disease $(\mathrm{N}=173)$

\begin{tabular}{lc}
\hline Therapy & $\begin{array}{c}\text { Number of } \\
\text { patients }(\%)\end{array}$ \\
\hline Regimen of therapy $(\mathrm{N}=173)$ & $14(8.1 \%)$ \\
No therapy & $159(91.9 \%)$ \\
1 regimen & $90(52.0 \%)$ \\
2 regimens & $13(7.5 \%)$ \\
3 regimens & \\
First line therapy $(\mathrm{N}=159)$ & $108(67.9 \%)$ \\
TKI & $19(11.9 \%)$ \\
mTORi & $12(7.5 \%)$ \\
Chemotherapy & $10(6.3 \%)$ \\
Cytokine & $7(4.4 \%)$ \\
Local treatment & $3(1.9 \%)$ \\
Others & \\
First line TKI therapy $(\mathrm{N}=108)$ & $89(82.4 \%)$ \\
Sunitinib & $10(9.3 \%)$ \\
Pazopanib & $9(8.3 \%)$ \\
Sorafenib & \\
First line mTORi therapy $(\mathrm{N}=19)$ & $2(10.5 \%)$ \\
Everolimus & $17(89.5 \%)$ \\
Temsirolimus & \\
Response to first line therapy & \\
(N=142 evaluable patients) & \\
Complete response $(\mathrm{CR})$ & $8(5.6 \%)$ \\
Partial response $(\mathrm{PR})$ & $25(17.6 \%)$ \\
Stable disease $(\mathrm{SD})$ & $58(40.8 \%)$ \\
Progression $(\mathrm{PD})$ & $51(35.9 \%)$ \\
Second line therapy $(\mathrm{N}=90 ; 52 \%)$ & $45(50.0 \%)$ \\
TKI & $33(36.7 \%)$ \\
mTORi & $1(1.1 \%)$ \\
Cytokine & $2(2.2 \%)$ \\
Chemotherapy & $1(1.1 \%)$ \\
Local treatment & \\
Others & \\
\hline & \\
&
\end{tabular}

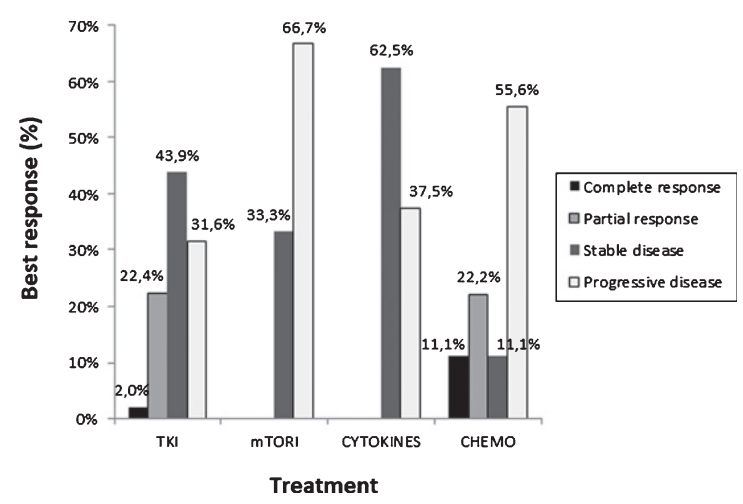

Fig. 1. Best response to treatment in first line setting.

$50 \%$ of patients, mainly axitinib and mTOR inhibitors in $36.7 \%$, mainly everolimus.

PFS could be evaluated in 157 patients and 119 events were recorded at the time of the analysis. The median PFS of first line therapy was 7.1 months [95\% CI 5.1-9.1] (Fig. 2). Figure 3 shows PFS according

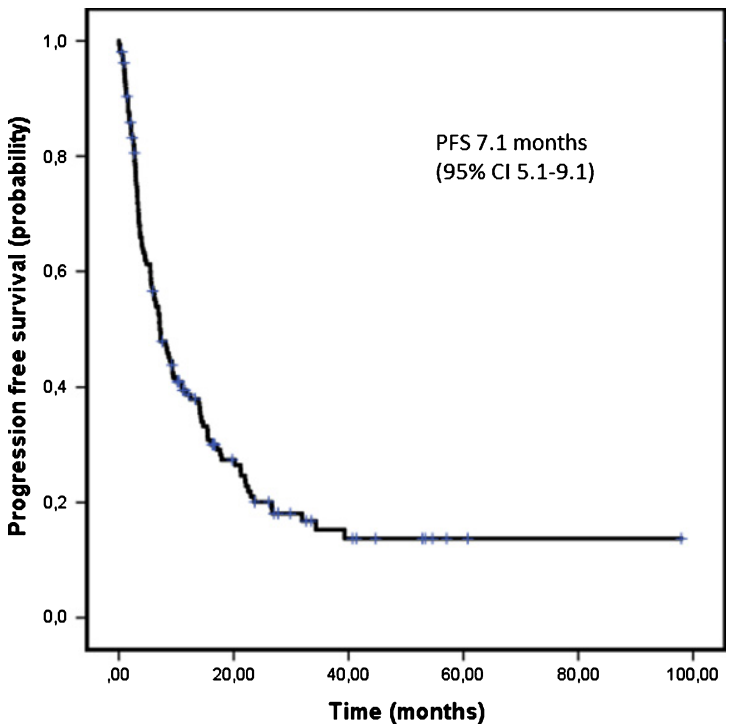

Fig. 2. First line progression free survival.

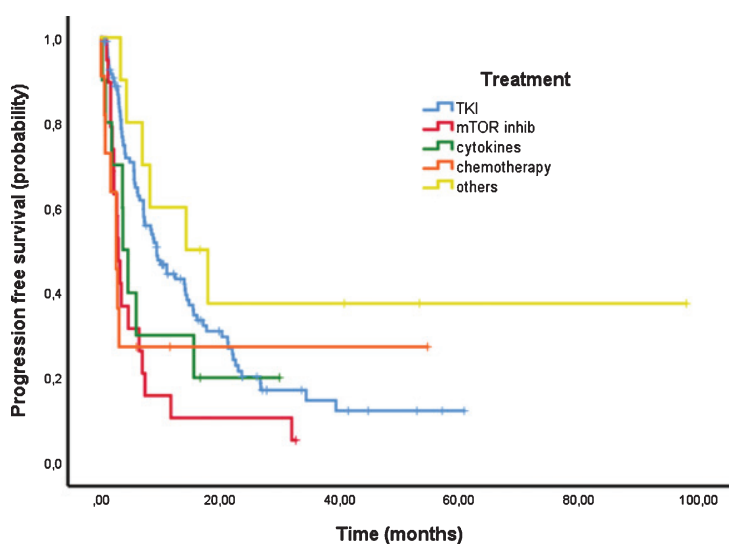

Fig. 3. Progression free survival (PFS) according to first line treatment.

to the first line treatment group. The longest PFS was reached with TKI of 9.3 months [95\% CI 6.1-12.5]. PFS of patients treated with mTOR inhibitors was 2.9 months [95\% CI 2.2-3.6], 3.6 months [95\% CI 2.2-5.1] with cytokines and 2.5 months [95\% CI $1.3-3.8]$ with chemotherapy.

At the time of the data cut-off point (April 1st, 2016), $126(72.8 \%)$ patients had died, with a median follow up of 15.2 months and the median OS was 17.9 months [95\% CI 15.0-20.9] (Fig. 4). OS according to histology was longer for papillary and chromophobe tumors (25.4 months and 19.6 months respectively) and lower for sarcomatoid (6.6 months) and unclassified tumors (2.3 months). Patients rated with a good 


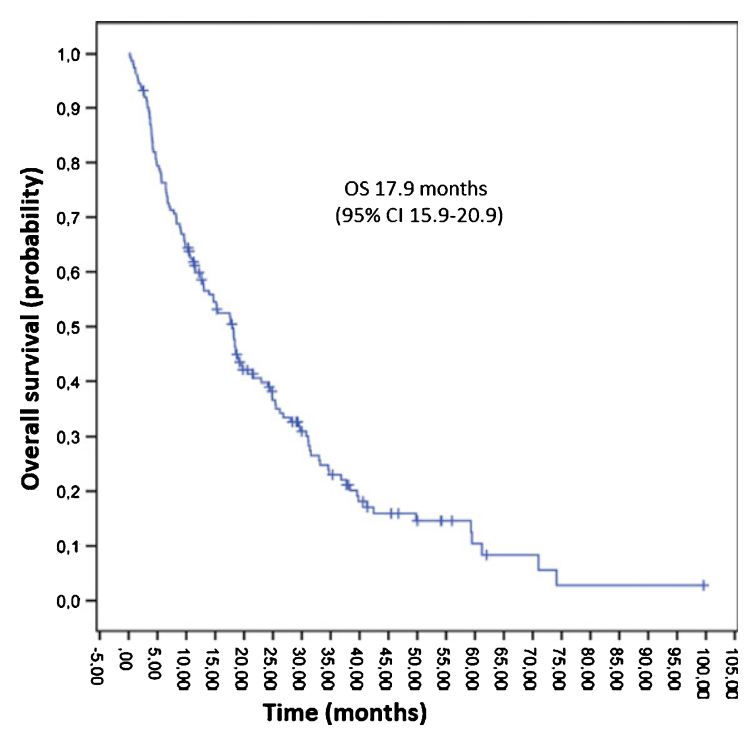

Fig. 4. Overall survival.

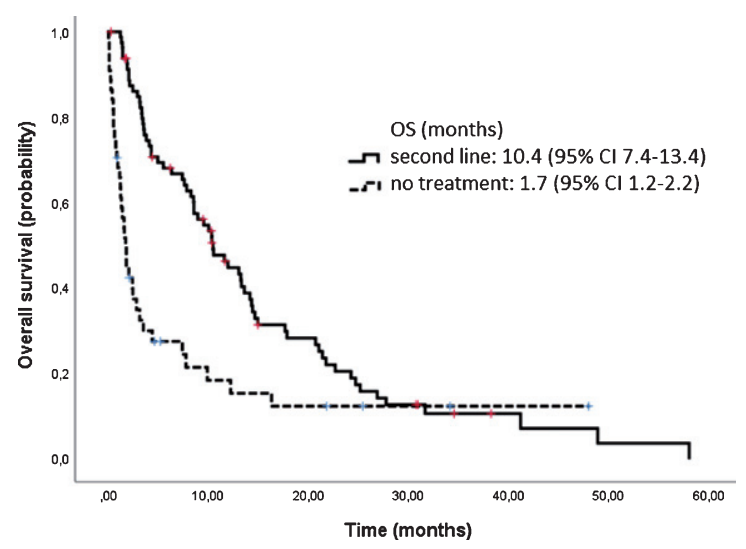

Fig. 5. Overall survival of second line treatment versus no treatment.

risk lived longer than those with an intermediate or poor risk ( $42.4 \mathrm{~m}$ vs $15.2 \mathrm{~m}$ vs $6.4 \mathrm{~m}$ ). After discontinuation of first line therapy, 89 patients were evaluable for subsequent treatment. Patients who received second line therapy had a longer survival than those who did not; 10.4 months [95\% CI 7.4-13.4] vs 1.7 months [95\% CI 1.2-2.2], (Fig. 5).

\section{DISCUSSION}

Non-clear cell renal cell carcinoma is a heterogeneous and uncommon disease. Outcome is worse than for ccRCC [3]. There is a paucity of data about the appropriate treatment for this type of malignancy. This retrospective study reports one of the largest cohorts of nccRCC patients published to date in order to assess the clinical management of these tumors the 'real-world' setting.

Most patients received sunitinib as a first line treatment. Although there is no standard treatment for nccRCC, there is substantial evidence based on retrospective series, small phase II and expanded access programs for the use of sunitinib as a targeted therapy. In addition, the European Society of Medical Oncology (ESMO) [4] guidelines highly recommend sunitinib as opposed to other options (IIA). Two prospective phase II randomized trials (ASPEN/ESPN) confirmed the efficacy of sunitinib versus everolimus in untreated nccRCC patients. In the ASPEN trial, sunitinib significantly increased progression-free survival (PFS) compared with everolimus in 108 patients with metastatic nccRCC; 8.3 months versus 5.6 months; HR 1.41 (80\% CI 1.03-1.92). Median OS was longer for sunitinib than for everolimus (31.5 months versus 13.2 months), although the association did not reach statistical significance (HR1.12 (95\% CI 0.7-2.1)) [5]. The ESPN trial explored the best treatment sequence. The study by Tannir et al. [6], enrolled 73 patients with metastatic nccRCC or ccRCC with $\geq 20 \%$ sarcomatoid features. Patients were randomized to receive sunitinib or everolimus as a first line therapy with crossover at disease progression. Everolimus did not demonstrate a superior efficacy with an OS of 14.9 months (95\% CI 8.0-23.4) compared to 16.2 months (95\% CI, 14.2-NA) with sunitinib as the first line $(p=0.18)$. In a similar way, Motzer et al. [7], compared first-line everolimus and sunitinib in a crossover treatment design in patients with metastatic renal cell carcinoma. About $15 \%$ of the study population had nccRCC. Median PFS for sunitinib in the first-line was 7.2 months versus 5.1 months for everolimus (HR 1.5; 95\% CI 0.9-2.8). The SUPAP study by GETUG assessed the efficacy of sunitinib in locally advanced and metastatic papillary renal cell carcinoma, demonstrating a significant activity with an OS of 17.8 months (95\% CI 5.7-26.1) and 12.4 months (95\% CI 8.2-14.3) in type 1 and 2, respectively [8].

More recently, another TKI, pazopanib, has been evaluated. In a retrospective analysis from the M. D. Anderson Cancer Center [9], twenty-nine patients with metastatic nccRCC received pazopanib. The median OS was 31 months in the first-line $(95 \% \mathrm{CI}$ 9.2-NA) and 13.6 months (95\% CI 6.4-NA) in the salvage group. In an Italian cohort, 37 patients were treated with pazopanib as a first line treatment. $81 \%$ 
of patients achieved disease control and the median PFS and OS were 15.9 (95\% CI 5.9-25.8) and 17.3 months (95\% CI 11.5-23.0), respectively [10]. Both studies support pazopanib as an alternative therapy.

In our study, 19 patients were treated with mTOR inhibitors as a first line treatment, 17 with temsirolimus and 2 with everolimus. These agents were prescribed as a second line in 33 patients, mainly everolimus. mTOR inhibitors also play an important role in the treatment of nccRCC. In a subgroup analysis of the Advanced Renal Cell Carcinoma (ARCC) trial, temsirolimus showed a superior efficacy over interferon in the non-clear cell histology and a similar OS to patients with ccRCC [11]. Everolimus also has a demonstrated activity in this type of tumors. In the REACT trial (Expanded Access Trial of Everolimus), 76 patients $(5.5 \%)$ had metastatic nccRCC and approximately $50 \%$ of patients achieved disease control with this mTOR inhibitor [12]. The phase II RAPTOR was designed to evaluate the efficacy of everolimus for papillary metastatic RCC as a first line. The median OS was 21.4 months (95\% CI 15.4-28.4), which was even longer for patients with type 1 papillary mRCC [13]. The MSKCC [14] performed a retrospective analysis of treatment outcome with mTOR inhibitors. Eighty five patients with nccRCC or renal carcinoma with sarcomatoid features were treated with temsirolimus or everolimus. OS was poor for the entire cohort (8.7 months; 95\% CI 6.5-12.0), although there were some patients who received treatment for more than 2 years. Therefore, there is a subset of patients who benefits from rapalogs.

Patients treated with TKI reached a longer median PFS than those treated with mTOR inhibitors (9.3 versus 2.9 months). Nevertheless, this may be influenced by the fact that patients treated with temsirolimus in the first line were mainly poor-risk patients (following the approved indication for the drug), while TKI-treated patients included all risk categories. Several meta-analysis have compared the activity of TKIs with mTOR inhibitors. One study included 332 patients from three phase II and one phase III randomized trials. TKIs significantly reduced the risk of progression versus mTOR inhibitors $(\mathrm{HR}=0.71$; $95 \%$ CI $0.60-0.84)$. This superiority was maintained when the analysis was limited to patients treated in the first line. However, there was no difference in OS between the two therapies when all the patients were evaluated together [15]. The meta-analysis by Fernández-Pello et al. [16], showed a trend towards a better survival for sunitinib compared to everolimus, although the difference did not reach statistical significance. Data for PFS from ESPN and ASPEN were included in this meta-analysis. The pooled analysis of these two studies generated a HR of $1.30(95 \%$ CI 0.91-1.86).

In our cohort, 58 (40.8\%) patients achieved stable disease as their best response. The rate of objective responses was low $(23.2 \%)$, as has been described in the previously mentioned studies. Similarly to these trials, we used the RECIST criteria, which is probably not the most appropriate tool to evaluate response with targeted therapies. In our study, the median PFS and OS were 7.1 and 17.9 months respectively. These results are in line with published data (Table 3). According to several studies, outcome in nccRCC is poorer than in ccRCC. In the RECORD3 study, the median OS was shorter for nccRCC with respect to ccRCC, regardless of the treatment sequence [17]. 49 studies comprising 1244 patients diagnosed of nccRCC and 6300 patients with ccRCC were evaluated in the meta-analysis by Vera-Badillo et al. [18]. A lower RR was observed in nccRCC compared to ccRCC and the median PFS was 7.4 months (2.7-8.6 months) and median OS was 13.4 months (6.6-25.6 months) for nccRCC only treated with targeted agents. With regard to ccRCC, the median PFS and median OS were 10.5 months (4.0-13.5 months) and 15.7 months (9.0-34.2 months), respectively.

We analyzed OS according to the different histologic subtypes. Papillary and chromophobe tumors reached the best outcome, as reported in previous studies [3, 6, 8, 19]. Unclassified and sarcomatoid carcinomas had a poor prognosis. We decided to include renal cell carcinomas with sarcomatoid features as this component confers an aggressive behavior and a worse response to targeted therapies [20, 21]. The International Metastatic Renal Cell Carcinoma Database Consortium (IMDC) [3] performed a large retrospective analysis based on 2215 patients with mRCC treated with first-line VEGF and mTOR inhibitors. The majority of nccRCC patients had a lower survival compared to ccRCC patients. Median OS was 27.1 months (95\% CI 12.6-75.3 months) for chromophobe tumors, 14.0 months (95\% CI 10.9-17.1 months) for papillary and 10.1 months (95\% CI 5.1-13.2 months) in unclassified renal cell carcinomas. In a subsequent larger series derived from the IMDC, a total of 230 patients were identified with sarcomatoid features. Approximately 93 percent of patients received VEGF-directed therapy in the first-line setting and the overall response rate was 21 percent. The median PFS and OS were 4.5 and 10.4 months, respectively [21]. 
Table 3

Selected clinical trials including patients with non-clear cell RCC

\begin{tabular}{|c|c|c|c|c|c|c|c|}
\hline Trial & Phase & $n$ & Histology & Treatment & ORR $(\%)$ & PFS (months) & OS (months) \\
\hline $\begin{array}{l}\text { Armstrong, } 2016 \\
\text { (ASPEN) }\end{array}$ & II & 108 & Any & $\begin{array}{l}\text { Sunitinib vs } \\
\text { Everolimus }\end{array}$ & 18 vs 9 & 8.3 vs 5.6 & 31.5 vs 13.2 \\
\hline $\begin{array}{l}\text { Tannir, } 2016 \\
\text { (ESPN) }\end{array}$ & II & 68 & Any & $\begin{array}{l}\text { Sunitinib vs } \\
\text { Everolimus }\end{array}$ & 9 vs 3 & 6.1 vs 4.1 & 16.2 vs 14.9 \\
\hline $\begin{array}{l}\text { Motzer, } 2014 \\
\text { RECORD-3 }\end{array}$ & II & 66 & Any & $\begin{array}{l}\text { Sun } \rightarrow \text { Eve vs } \\
\text { Eve } \rightarrow \text { Sun }\end{array}$ & 16.8 vs 16.2 & 7.2 vs 5.1 & - \\
\hline $\begin{array}{l}\text { Ravaud, } 2015 \\
\text { (SUPAP) }\end{array}$ & II & 61 & Papillary & Sunitinib & $\begin{array}{l}\text { Type } 1: 13 \\
\text { Type } 2: 11\end{array}$ & $\begin{array}{l}\text { Type } 1: 6.6 \\
\text { Type } 2: 5.5\end{array}$ & $\begin{array}{l}\text { Type } 1: 17.8 \\
\text { Type } 2: 12.4\end{array}$ \\
\hline $\begin{array}{l}\text { Dutcher, } 2009 \\
\text { (ARCC) }\end{array}$ & III & $\begin{array}{l}73 \text { (poor } \\
\text { risk) }\end{array}$ & $\begin{array}{l}\text { Papillary } \\
\text { Chromophobe } \\
\text { Collecting duct }\end{array}$ & $\begin{array}{l}\text { Temsirolimus } \\
\text { vs } \\
\text { Interferon- } \alpha\end{array}$ & 5.4 vs 8.3 & 7.0 vs 1.8 & 11.6 vs 4.3 \\
\hline $\begin{array}{l}\text { Escudier, } 2016 \\
\text { (RAPTOR) }\end{array}$ & II & 92 & Papillary & Everolimus & $1 \%$ & 4.1 & 21.4 \\
\hline
\end{tabular}

Abbreviations: ORR: objective response rate; PFS: progression free survival; OS: overall survival.

Response to treatment differs between different histological subtypes. In the ASPEN trial, papillary and unclassified tumors reached a longer PFS with sunitinib (8.1 months and 11.5 months, respectively) than with everolimus (5.5 months and 5.7 months, respectively). Whereas, tumors with a chromophobe histology responded better to everolimus (11.4 months for everolimus and 5.5 months for sunitinib) [5]. In the ESPN trial, the median OS with sunitinib for papillary RCC was 16.6 months and 31.6 months for chromophobe. Shorter survival rates were reached with everolimus for these histological types. The median OS for unclassified tumors was 15.4 months with sunitinib and a poorer survival was observed for RCC with sarcomatoid features compared to tumors without sarcomatoid features (10.4 months versus 16.6 months) [6]. There are two studies which evaluate different targeted therapies as first line therapies in papillary renal cell carcinomas. Patients received sunitinib in the SUPAP trial, whereas everolimus was the agent of choice in the RAPTOR trial [8, 13]. Similar PFS rates were reported in these two trials. However, the OS reported in the second study was longer. Patients treated with everolimus achieved a median OS of 28.0 months (95\% CI 7.6-NE) for type 1 histology and 24.2 months (95\% CI 15.8-32.8) for type 2. In the SUPAP trial, the median OS was 17.8 months $(95 \%$ CI 5.7-26.1) and 12.4 months (95\% CI 8.2-16) for type 1 and type 2, respectively. In the PANORAMA study, papillary histology was associated with a better overall survival with pazopanib according to the univariate analysis compared with other subtypes of nccRCC [10]. In the retrospective analysis by MSKCC [14], response to mTOR inhibitors for sarcomatoid histological tumors was poor. Most of patients showed progressive disease as their best response and a short survival; PFS was 3.5 months $(95 \% \mathrm{CI}$ 1.6-5.4) and OS was 8.2 months (95\% CI 4.8-14.3).

Poor risk RCC seems to achieve a better response to mTOR inhibitors than TKIs, as reported in ASPEN trial, with a longer PFS with everolimus than sunitinib (6.1 months versus 4.0 months) [5]. Outcome was also better in patients with a poor prognosis treated with temsirolimus compared to interferon alfa in the pivotal phase 3 [11]. Therefore, outcome and response to treatment differ between different histological subtypes that reflects distinct molecular characteristics and behavior. Although important advances have been reached in the treatment of nccRCC, outcomes are still unsatisfactory. In recent years, an enhanced understanding of the molecular basis of these tumors has led to the development of more specific and effective therapies. Several clinical trials are ongoing in this area (Table 4).

The Cancer Genome Atlas Research Network [22] has performed a comprehensive molecular characterization of papillary renal carcinoma. Altered MET status (mutation, splice variant or gene fusion) or amplification of this gene is associated with type 1 papillary renal cell carcinoma, whereas activation of the NRF2-ARE pathway is associated with type 2.

Foretinib, a dual MET-VEGFR2 inhibitor, has demonstrated activity in patients with metastatic papillary renal cell cancer. In a phase II trial that included 74 patients with this histologic subtype, the objective response rate was 13.5 percent and the median PFS was nine months. The OS rate was 70 percent at one year and the presence of a MET mutation (mainly a germ line mutation) was a predictive factor of response [23]. 
Table 4

Ongoing clinical trials including patients with non-clear cell RCC

\begin{tabular}{|c|c|c|c|c|c|}
\hline Clinical trial & $\begin{array}{c}\text { Study } \\
\text { Description }\end{array}$ & Agent & Histology & Primary outcome & Status \\
\hline NCT 03091192 & Phase III & $\begin{array}{l}\text { Savolitinib vs } \\
\text { Sunitinib }\end{array}$ & $\begin{array}{l}\text { MET-driven } \\
\text { papillary RCC }\end{array}$ & PFS & Active, not recruiting \\
\hline NCT 02761057 & Phase II & $\begin{array}{l}\text { MET kinase inhibitors } \\
\text { (Cabo/Crizo/ } \\
\text { Savolitinib) vs } \\
\text { Sunitinib }\end{array}$ & Papillary RCC & PFS & $\begin{array}{l}\text { Suspended (scheduled } \\
\text { interim monitoring) }\end{array}$ \\
\hline NCT 02504892 & Phase II & Everolimus & $\begin{array}{l}\text { BHD- } \\
\text { associated } \\
\text { kidney cancer } \\
\text { or Sporadic } \\
\text { chromophobe }\end{array}$ & ORR & $\begin{array}{r}\text { Recruitment } \\
\text { terminated }\end{array}$ \\
\hline NCT 01399918 & Phase II & $\begin{array}{l}\text { Everolimus }+ \\
\text { Bevacizumab }\end{array}$ & Any nccRCC & $\begin{array}{l}\text { OS and PFS at } 6 \\
\text { months }\end{array}$ & Active, not recruiting \\
\hline NCT 02915783 & Phase II & $\begin{array}{l}\text { Lenvatinib + } \\
\text { Everolimus }\end{array}$ & Any nccRCC & ORR & Recruiting \\
\hline NCT 03075423 & Phase II & $\begin{array}{l}\text { Nivolumab + } \\
\text { Ipilimumab vs } \\
\text { Sunitinib }\end{array}$ & Any nccRCC & OS at 12 months & Recruiting \\
\hline NCT 02853344 & Phase II & Pembrolizumab & Any nccRCC & ORR & Active, not recruiting \\
\hline NCT 02724878 & Phase II & $\begin{array}{l}\text { Atezolizumab + } \\
\text { Bevacizumab }\end{array}$ & $\begin{array}{l}\text { Any } \\
\text { nccRCC/ccRCC } \\
\text { with } \geq 20 \% \\
\text { sarcomatoid } \\
\text { features }\end{array}$ & ORR & Recruiting \\
\hline NCT 01185366 & Phase II & $\begin{array}{l}\text { Everolimus vs } \\
\text { Sunitinib }\end{array}$ & $\begin{array}{l}\text { Any nccRCC/ } \\
\text { Sarcomatoid } \\
\text { features }\end{array}$ & PFS & Active, not recruiting \\
\hline NCT 03177239 & Phase II & $\begin{array}{l}\text { Nivolumab followed } \\
\text { by Nivolumab }+ \\
\text { Ipilimumab }\end{array}$ & $\begin{array}{l}\text { Any nccRCC/ } \\
\text { Sarcomatoid } \\
\text { features }\end{array}$ & ORR & Recruiting \\
\hline NCT 01767636 & Phase II & Pazopanib & $\begin{array}{l}\text { Any nccRCC/ } \\
\text { Sarcomatoid }\end{array}$ & OS at 12 months & Active, not recruiting \\
\hline
\end{tabular}

Abbreviations: RCC: renal cell carcinoma; nccRCC: non-renal cell renal cell carcinoma; PFS: progression free survival; ORR: objective response rate; OS: overall survival; BHD: Birt-Hogg- Dubé.

Another selective MET inhibitor, savolitinib, has been evaluated in a phase II study of 109 patients with advanced papillary renal cell cancer. Outcomes were reported according to MET status. An objective response was observed in $18 \%$ patients, all with MET-driven disease. PFS was significantly longer in this group of patients compared to patients with MET-independent tumors (6.2 months versus 1.4 months; HR 0.33; 95\% CI 0.20-0.52) [24]. A phase III clinical trial comparing savolitinib to sunitinib is planned in patients with MET-driven papillary RCC (NCT 03091192). Clinical trials are ongoing with other MET suppressors such as cabozantinib (NCT 02761057).

Alterations in the AKT-mTOR pathway are involved in the development of chromophobe tumors, primarily in Birt-Hogg-Dubé syndrome [25]. A trial with everolimus based on this histology is under- way (NCT 02504892). The combined blockade of the mTOR and VEGF pathways is being explored in different clinical trials (NCT 01399918; NCT 02915783). PD-L1 expression appears to be associated with a worse prognosis in nccRCC [26]. The immune-checkpoint inhibitor nivolumab has recently been approved for the treatment of ccRCC. PD-1/PDL-1 inhibitors such as nivolumab (NCT 03075423), pembrolizumab (NCT 02853344) and atezolizumab (NCT 02724878) are being tested in nccRCC.

We acknowledge several limitations in our study such as its retrospective nature, the heterogeneous study population with mixed histologies and different treatments. Furthermore, some data are lacking. Despite these limitations, our study provides an accurate picture of the management of nccRCC in the real-world setting. 


\section{CONCLUSIONS}

The clinical outcome reported in this study shows similar survival rates to those published in other studies, although there is a substantial difference among the distinct subtypes. In general, nccRCC prognosis remains poor. Collaboration between centers and cooperative groups should promote the enrolment of patients with nccRCC into specific randomized clinical trials that include appropriate stratification and subgroup analysis. Research efforts are needed to find molecular alterations of each histological type in order to develop specific therapies and to identify predictive biomarkers that could be used as tools in the future.

\section{ACKNOWLEDGMENTS}

None.

\section{CONFLICTS OF INTEREST}

Almudena Martín: Advisory Boards: Janssen, Sanofi; Speaker honoraria: Astra Zeneca, BMS, Janssen; Travel expenses: Pfizer, Roche, Pharmamar; Clinical trials: Pfizer, Aveo.

Javier Puente: Advisory Boards: Bayer, Roche, Ipsen, Eusa Pharma, Pfizer, BMS, Novartis, Eisai; Speaker honoraria: Pfizer, BMS, MSD, Roche, Novartis; Travel expenses: Pfizer, BMS; Clinical trials: Roche, Pfizer, Eisai, Ipsen, BMS, MSD.

Alvaro Pinto: None.

Pablo Gajate: None.

Teresa Alonso: Advisory Boards: Ipsen; Speaker honoraria: Pfizer; Travel expenses: Pfizer; Clinical trials: Roche, Pfizer, Eisai, Ipsen, BMS, MSD.

Enrique Grande: Advisory Boards/Speaker honoraria: Pfizer, Ipsen, Eisai, BMS, Roche; Research grants: Pfizer, Astra Zeneca, Roche and Ipsen.

Ana Herrero: None.

Constanza Maximiano: None.

María Garrido: None.

Isabel Gallegos: None.

$M^{a}$ Laura Villalobos: None.

Jesús García-Donas: None.

Edinson Caviedes: None.

Iciar García: Advisory Boards/Speaker honoraria: Bayer, Roche, Ipsen, Pfizer, Novartis; Travel expenses: Pfizer, BMS; Clinical trials: Roche, Pfizer, Eisai.
Javier Espinosa: Speaker honoraria: Astellas, Janssen, Pfizer, Novartis e Ipsen.

Carlos Aguado: Advisory Boards: Boehringer, Pierre Fabre; Travel expenses: Roche; Clinical trials: Roche, Eisai, MSD.

José Angel Arranz: Advisory Boards: Pfizer, Novartis; Research funding (SOGUG): BMS, PierreFabre, Novartis; Clinical trials: MSD, BMS, Roche, Astellas, Janssen-Cilag, Astra-Zeneca.

Lourdes García: None.

Juan Francisco Rodríguez: Advisory boards/Consulting: BMS; Speaker honoraria: Roche, BMS, Novartis, MSD, Janssen, Pfizer, Astra-Zeneca; Travel expenses: Astellas, Novartis, Roche, BMS, Pfizer, MSD; Corporate-sponsored research: Astra-Zeneca.

Javier Casinello: None.

Laura Rodriguez: None.

\section{REFERENCES}

[1] Siegel RL, Miller KD, Jemal A. Cancer statistics, 2016. CA Cancer J Clin. 2016; 66 (1): 7-30.

[2] Sankin A, Hakimi AA, Hsieh JJ, Molina AM. Metastatic non-clear cell renal cell carcinoma: An evidence based review of current treatment strategies. Front Oncol. 2015; 5:67.

[3] Kroeger N, Xie W, Lee JL, Bjarnason GA, Knox JJ, MacKenzie MJ, et al. Metastatic non-clear cell renal cell carcinoma treated with targeted therapy agents: Characterization of survival outcome and application of the International mRCC Database Consortium Criteria. Cancer. 2013;119(16):2999-3006.

[4] Escudier B, Porta C, Schmidinger M, Rioux-Leclercq N, Bex A, Khoo V, et al. Renal cell carcinoma: ESMO Clinical Practice Guidelines for diagnosis, treatment and follow-up. ESMO Guidelines Committee. Ann Oncol. 2016 Sep;27(suppl 5): v58-v68.

[5] Armstrong AJ, Halabi S, Eisen T, Broderick S, Stadler WM, Jones RJ, et al. Everolimus versus sunitinib for patients with metastatic non-clear cell renal cell carcinoma (ASPEN): A multicentre, open-label, randomised phase 2 trial. Lancet Oncol. 2016;17(3):378-88.

[6] Tannir NM, Jonasch E, Albiges L, Altinmakas E, Ng CS, Matin SF, et al. Everolimus versus sunitinib prospective evaluation in metastatic non-clear cell renal cell carcinoma (ESPN): A randomized multicentre phase 2 trial. Eur Urol. 2016;69:866-74.

[7] Motzer RJ, Barrios CH, Kim TM, Falcon S, Cosgriff T, Harker WG, et al. Phase II randomized trial comparing sequential first-line everolimus and second-line sunitinib versus first-line sunitinib and second-line everolimus in patients with metastatic renal cell carcinoma. J Clin Oncol. 2014;32:2765-72.

[8] Ravaud A, Oudard S, de Fromont M, Chevreau C, Gravis G, Zanetta S, et al. First-line treatment with sunitinib for type 1 and type 2 locally advanced or metastatic papillary renal cell carcinoma: A phase II study (SUPAP) by the French genitourinary group (GETUG). Ann Oncol. 2015;26:1123-28. 
[9] Matrana MR, Baiomy A, Campbell M, Alamri S, Shetty A, Teegavarapu $\mathrm{P}$, et al. Outcomes of patients with metastatic non-clear-cell renal cell carcinoma treated with pazopanib. Clin Genitourin Cancer. 2016;15(2):e205-8.

[10] Buti S, Bersanelli M, Maines F, Facchini G, Gelsomino F, Zustovich F, et al. First-line pazopanib in non-clear-cell renal carcinoma: The Italian retrospective multicentre PANORAMA study. Clin Genitourin Cancer. 2016;15(4):e609-14.

[11] Dutcher JP, de Souza P, McDermott D, Figlin RA, Berkenblit A, Thiele A, et al. Effect of temsirolimus versus interferon- $\alpha$ on outcome of patients with advanced renal cell carcinoma of different tumor histologies. Med Oncol. 2009;26(2):202-9.

[12] Grünwald V, Karakiewicz PI, Bavbek SE, Miller K, Machiels JP, Lee SH, et al. An international expandedaccess programme of everolimus: Addressing safety and efficacy in patients with metastatic renal cell carcinoma who progress after initial vascular endothelial growth factor receptor-tyrosine kinase inhibitor therapy. Eur $\mathbf{J}$ Cancer. 2012;48(3):324-32.

[13] Escudier B, Molinie V, Bracarda S, Maroto P, Szczylik C, Nathan P, et al. Open-label phase 2 trial of firstline everolimus monotherapy in patients with papillary metastatic renal cell carcinoma: RAPTOR final analysis. Eur J Cancer. 2016;69:226-35.

[14] Voss MH, Bastos DA, Karlo CA, Ajeti A, Hakimi AA, Feldman DR, et al. Treatment outcome with mTOR inhibitors for metastatic renal cell carcinoma with nonclear and sarcomatoid histologies. Ann Oncol. 2014;25(3): 663-68.

[15] Ciccarese C, Iacovelli R, Brunelli M, Massari F, Bimbatti $\mathrm{D}$, Fantinel E, et al. Addressing the best treatment for non-clear cell renal cell carcinoma: A meta-analysis of randomised clinical trials comparing VEGFR-TKis versus mTORi-targeted therapies. Eur J Cancer. 2017;83:237-46.

[16] Fernández-Pello S, Hofmann F, Tahbaz R, Marconi L, Lam TB, Albiges L, et al. A systematic review and metaanalysis comparing the effectiveness and adverse effects of different systemic treatments for non-clear cell renal cell carcinoma. Eur Urol. 2017;71:426-36.

[17] Knox JJ, Barrios CH, Kim TM, Cosgriff T, Srimuninnimit V, Pittman K, et al. Final overall survival analysis for the phase II RECORD-3 study of first-line everolimus followed by sunitinib versus first-line sunitinib followed by everolimus in metastatic RCC. Ann Oncol. 2017; 28(6): 1339-1345

[18] Vera-Badillo FE, Templeton AJ, Duran I, Ocana A, de Gouveia P, Aneja P, et al. Systemic therapy for non-clear cell renal cell carcinomas: A systemic review and metaanalysis. Eur Urol. 2015;67(4):740-9.

[19] Colomba E, Le Teuff G, Eisen T, Stewart GD, Fife K, Larkin J, et al. Metastatic chromophobe renal cell carcinoma treated with targeted therapies: A Renal Cross Channel Group study. Eur J Cancer. 2017;80:55-62.

[20] Golshayan AR, George S, Heng DY, Elson P, Wood LS, Mekhail TM, et al. Metastatic sarcomatoid renal cell carcinoma treated with vascular endothelial growth factortargeted therapy. J Clin Oncol. 2009; 27(2): 235-41.

[21] Kyriakopoulos CE, Chittoria N, Choueiri TK, Kroeger N, Lee JL, Srinivas S, et al. Outcome of patients with metastatic sarcomatoid renal cell carcinoma: Results from the International Metastatic Renal Cell Carcinoma Database Consortium. Clin Genitourin Cancer. 2015; 13(2): e79-85.

[22] Linehan VM, Spellman PT, Ricketts CJ, Creighton CJ, Fei SS, Davis C, et al. Cancer genome atlas research network. Comprehensive molecular characterization of papillary renal-cell carcinoma. N Engl J Med. 2016; 374 (2): 135-45.

[23] Choueiri TK, Vaishampayan U, Rosenberg JE, Logan TF, Harzstark AL, Bukowski RM, et al. Phase II and biomarker study of the dual MET/VEGFR2 inhibitor foretinib in patients with papillary renal cell carcinoma. J Clin Oncol. 2013;31(2):181-6.

[24] Choueiri TK, Plimack E, Arkenau HT, Jonasch E, Heng DY, Powles T, et al. Biomarker-based phase II trial of savolitinib in patients with advanced papillary renal cell cancer. J Clin Oncol. 2017;35(26):2993-3001.

[25] Linehan WM. Genetic basis of kidney cancer: Role of genomics for the development of disease-based therapeutics. Genome Res. 2012;22(11):2089-100.

[26] Choueiri TK, Fay AP, Gray KP, Callea M, Ho TH, Albiges $\mathrm{L}$, et al. PD-L1 expression in nonclear-cell renal cell carcinoma. Ann Oncol. 2014;25(11):2178-84. 